\title{
Acalypha wilkesiana extracts induce apoptosis by causing single strand and double strand DNA breaks
}

\begin{abstract}
Ethnopharmacological relevance: The seeds of Acalypha wilkesiana have been used empirically by traditional healers in Southwest Nigeria together with other plants as a powder mixture to treat patients with breast tumours and inflammation.

Aim of the study: There is an increasing interest among researchers in searching for new anticancer drugs from natural resources, particularly plants. This study aimed to investigate the anticancer properties of Acalypha wilkesiana extracts and the characteristics of DNA damage against brain and lung cancer cells.

Materials and methods: The antiproliferative activity of Acalypha wilkesiana extracts (ethyl acetate, hexane, and ethanol) was examined on human glioma (U87MG), human lung carcinoma (A549), and human lung fibroblast (MRC5) cells.

Results: Cell viability MTT assay revealed that ethyl acetate extract of the plant possessed significant antiproliferative effects against both U87MG (GI50 = $28.03 \pm 6.44 \mathrm{gg} / \mathrm{ml})$ and A549 $(\mathrm{GI} 50=89.63 \pm 2.12 \mathrm{gg} / \mathrm{ml})$ cells $(\mathrm{p}$ value $<0.0001)$. The hexane extract was found to exhibit crucial antiproliferative effects on U87MG (GI50 = 166.30 $\pm 30.50 \mathrm{gg} / \mathrm{ml})(\mathrm{p}$ value < 0.0001 ) but not on A549 cells. Neither plant extract possessed noticeable antiproliferative effects on the non-cancerous MRC5 cells (GI50 > $300 \mathrm{\varepsilon g} / \mathrm{ml}$ ). The ethanol extract showed no antiproliferative effects on any cell line examined. Haematoxylin \& Eosin ( $\mathrm{H} \& \mathrm{E})$ staining and single cell gel electrophoresis (SCGE) comet assay confirmed that plant extract-treated cells underwent apoptosis and not necrosis. SCGE comet assays confirmed that plant extracts caused both single strand (SSB) and double strand (DSB) DNA breaks that led to the execution of apoptosis.
\end{abstract}

Conclusion: The extracts (especially ethyl acetate and hexane) of Acalypha wilkesiana possess valuable cytotoxic effects that trigger apoptosis in U87MG and A549 cancer cells through induction of DNA SSBs and DSBs.

Keyword: Acalypha wilkesiana; Antiproliferative effect; Apoptosis; DNA damage; Human glioma; Human lung carcinoma 